\title{
Clinical Characteristics in a Sample of Transsexual People
}

\section{Características clínicas de uma amostra de pessoas transexuais}

\author{
Maria Rita Lerri ${ }^{1}$ Adriana Peterson Mariano Salata Romão ${ }^{1}$ Manoel Antônio dos Santos ${ }^{2}$ Alain Giami ${ }^{3}$ \\ Rui Alberto Ferriani ${ }^{1}$ Lúcia Alves da Silva Lara ${ }^{1}$
}

${ }^{1}$ Department of Gynecology and Obstetrics, Faculdade de Medicina de Ribeirão Preto, Universidade de São Paulo, Ribeirão Preto, São Paulo, Brazil

2 Faculdade de Filosofia, Ciências e Letras de Ribeirão Preto, Universidade de São Paulo, Ribeirão Preto, São Paulo, Brazil

${ }^{3}$ Center for Research in Epidemiology and Population Health (CESP), Institut National de la Santé et de la Recherche Médicale (Iserm) Unit 1018, Team Gender, Sexual and Reproductive Health, Paris, France
Address for correspondence Maria Rita Lerri, MSc, Faculdade de Medicina de Ribeirão Preto, Universidade de São Paulo, Av. Bandeirantes, 3900, 14049-900, Ribeirão Preto, SP, Brasil (e-mail: mrlerri@yahoo.com.br).

Rev Bras Ginecol Obstet 2017;39:545-551.

\begin{abstract}
Keywords

- transsexual

- gender dysphoria

- anxiety

- depression

- sex reassignment surgery
\end{abstract}

\section{Resumo}

Purpose To assess the clinical characteristics of subjects with gender dysphoria (GD). Method A cross-sectional study of adults with GD. Symptoms of anxiety and depression were measured using the Hospital Anxiety and Depression Scale (HADS). Sociodemographic data, clinical data and life habits were recorded.

Results Total of 44 subjects participated in the study: 36 (82\%) trans women and 8 (18\%) trans men. Forty-three (98\%) of the GD patients had anxiety (36 [100\%] trans women and 7 [87.5\%] trans men), and 36 (82\%) had depression (29 [80.5\%] trans women and 7 [87.5\%] trans men). Suicide had been attempted by $32(73 \%)$ subjects. The rates of depression were lower among the subjects living with partners, parents, or other people than among those living alone $(p=0.03)$, and it was also lower among the subjects who were married compared to those who were dating or single $(p=0.03)$.

Conclusion Improving the relationship status may reduce the prevalence of depressive symptoms in GD patients. There was a high rate of attempted suicide in this sample.

Objetivo Avaliar as características clínicas de indivíduos com disforia de gênero (DG). Método Estudo transversal com pessoas transexuais. Os sintomas de ansiedade e depressão foram medidos usando a Escala Hospitalar de Ansiedade e Depressão. Os dados sociodemográficos, os dados clínicos, e os hábitos de vida foram registrados por meio de um questionário.

Resultados Um total de 44 indivíduos participou do estudo: 36 (82\%) mulheres trans, e $8(18 \%)$ homens trans. Quarenta e três $(98 \%)$ destes apresentaram ansiedade, sendo received

August 15, 2016

accepted

May 5, 2017

published online

August 7, 2017
DOI https://doi.org/

10.1055/s-0037-1604134. ISSN 0100-7203.
Copyright $\odot 2017$ by Thieme Revinter

Publicações Ltda, Rio de Janeiro, Brazil
License terms

(c) (i) $\ominus$ (\$) 


Palavras-chave
- transexuais
- disforia de gênero
- ansiedade
- depressão
- cirurgia de
redesignação sexual

$36(100 \%)$ mulheres trans e $7(87,5 \%)$ homens trans, e $36(82 \%)$ apresentaram depressão, sendo $29(80,5 \%)$ mulheres trans, e $7(87,5 \%)$ homens trans. Um total de $32(73 \%)$ indivíduos já haviam tentado suicídio. Os indivíduos que vivem com parceiros, pais ou outras pessoas tiveram uma menor taxa de depressão do que aqueles que vivem sozinhos $(p=0,03)$, e os indivíduos que eram casados tiveram uma menor taxa de depressão do que aqueles que estavam namorando ou solteiros $(p=0,03)$.

Conclusão A melhoria do status de relacionamento pode reduzir a prevalência de sintomas depressivos em pessoas transexuais. Encontrou-se uma alta taxa de tentativas de suicídio nessa amostra.

\section{Introduction}

Gender dysphoria (GD) is the distress caused by the feeling that one is a member of the sex that does not match one's physical appearance. Thus, individuals with GD identify strongly with the other sex, and experience discomfort and inadequacy with their given biological sex. Individuals with GD have marked inconsistencies between the gender they were assigned (usually at birth, known as gender birth) and the experienced/expressed gender. ${ }^{1,2}$ However, the heterogeneity of the trans population in terms of self-perception indicates the complexity of defining GD based on the needs of the individuals for hormonal treatments and sex reassignment surgery (SRS). ${ }^{3}$ Epidemiological data indicate that the rate of GD is of 1 in 11,900 biological males, and of 1 in 30,400 biological females. ${ }^{4,5}$ However, there are discrepancies in the estimates from different countries due to inconsistent diagnostic criteria, cultural differences, and limited availability of specialized services for diagnosis and treatment. ${ }^{6}$ The etiology of GD is unknown, although some previous studies suggested a biological basis, and other studies suggested a psychological basis. ${ }^{6}$

Gender dysphoria often manifests in childhood, and the typical feelings of incongruence seem to increase with age, mainly during adolescence, when these feelings tend to be more prominent, ${ }^{7}$ and when subjects with GD may begin to look for medications or surgery for sex reassignment. ${ }^{8}$ The lack of acceptance of one's appearance can generate intense suffering, and this suffering often declines when surgical and hormonal treatments lead to changes in appearance. This, in turn, motivates individuals with GD to change official records regarding details such as their name and gender.

Thus, individuals with GD often experience distress and suffering, and their profound rejection of their biological $\mathrm{sex}^{8}$ can trigger emotional, affective, and psychosocial problems that may be exacerbated by the obligation to behave in a manner compatible with their biological sex. Transgender persons are often not accepted by their families, schools, and coworkers, and this may impair their educational and professional achievements. ${ }^{9}$ The difficulties in acceptance become more acute with age, and often compel transgender persons to engage in activities with minimal professional qualifications. ${ }^{10}$ These may increase the exposure of this population to risky situations and behaviors, ${ }^{11}$ such as abuse of psychoactive substances, ${ }^{12}$ violence, and exposure to the human immunodeficiency virus (HIV) and other sexually transmitted infections (STIs). ${ }^{11,13}$ When transgender persons use healthcare services, they are less likely to engage in these high-risk behaviors. ${ }^{11}$

Unfortunately, when seeking healthcare services for sex reassignment, transgender persons face many barriers, including the scarcity of specialized services, difficulties in accessing these services, and the high costs. ${ }^{5,14}$ Although the positive effects of surgery are widely recognized, ${ }^{15}$ and standards for the care of transgender individuals are available, SRS is only performed in the public hospitals of a few countries. ${ }^{3}$ The barriers faced by transgender persons, in addition to intolerance and lack of social support, can lead to psychological problems. This further compromises their interpersonal relations and quality of life, and frequently leads to depressive symptoms and anxiety disorders., ${ }^{90,16,17}$ The increased vulnerability of these individuals to depression is indicated by their high rates of suicide and attempted suicide. ${ }^{10,18}$

Despite recent advances in the technology of SRS and endocrine treatment, there can be intense demands on medical professionals to care for these individuals. However, little is known about the factors associated with depression and anxiety in this population. The objective of the present study was to determine the sociodemographic and clinical factors of a population of subjects with GD who were followed-up at a university Sex Medicine Service.

\section{Methods}

This was a cross-sectional study conducted among a nonprobabilistic convenience sample of transsexual patients followed up at the Outpatient Clinic of Studies of Human Sexuality of the Department of Gynecology and Obstetrics from March 2013 to June 2014. Gender dysphoria was defined according to the Diagnostic and Statistical Manual of Mental Disorders, 5th edition (DSM-5), criteria as a marked incongruity between the expressed gender and the gender assigned at birth, lasting at least six months, and manifesting at least two of the following criteria: marked incongruity between the expressed gender and the primary and/or secondary sexual characteristics; a strong desire to get rid of their own primary and/ or secondary sexual characteristics or, in adolescents, a desire to prevent the development of secondary sexual characteristics; and a strong desire to be treated as the other genre. The condition is associated with clinically significant distress or 
impairments in social, occupational, or other important areas of life. ${ }^{2}$

A psychologist invited 50 female to male (FtM) and male to female (MtF) individuals (aged between 18 to 59 years) to participate in the study while they were in the waiting room of the clinic. All subjects were at least 18 years old, and had at least 2 previous consultations at the service. Individuals with signs of cognitive deficiency, based on investigator observation or medical records, were excluded. All participating subjects provided written informed consent. The research was conducted according to the Helsinki Declaration, which was revised in 2008 .

In a room reserved for psychological care, the investigator performed an individual semi-structured audio-recorded interview to obtain sociodemographic data (schooling, occupation, professional activity, family income, marital status, place of residence, living partner, type of dwelling, and religion), and data about life habits (smoking, family support, alcoholism, and drug addiction), marital status, clinical symptoms (reason for referral, current medications, and knowledge of the condition), social experience, rate of suicide attempts, and history of psychological and psychiatric treatments. Data regarding the diagnosis and treatment were obtained from the medical records.

After the interview, the participants answered individually the Hospital Anxiety and Depression Scale (HADS) to determine the presence of anxiety and depressive symptoms. This scale consists of 14 items, with 7 items investigating anxiety (HAD-A) and 7 items investigating depression (HAD-D). There are 4 possible answers for each item (the score ranges from 0 to 3 ), and the total score of each subscale ranges from 0 to 21 . The present study used a cut-off point of 8 or more for anxiety, and of 9 or more for depression. ${ }^{19}$

The study followed the ethical norms of Resolution 196/96 of the Brazilian National Health Council for research with human beings, and was approved by the Research Ethics Committee of the University Hospital (protocol no. 13120/2012).

\section{Statistical Analysis}

Fisher's exact test was used to determine the association of the different variables (attempted suicide, feeling discriminated against, marital status, age, monthly income, co-habitation status) with anxiety and depression. The simple and multiple exact logistic regression methods described by Cox $(1970)^{20}$ were used to estimate the crude and adjusted odds ratios (ORs). A stepwise method for the explanatory variables was used in the logistic regression. All analyses were performed using the SAS (SAS Institute, Cary, NC, US) software, version 9.2 , and $p$-values $<0.05$ were considered significant.

\section{Results}

We excluded 6 of the 50 subjects initially screened: 2 who refused to answer the semi-structured questionnaire for fear of exposure, and 4 who did not attend the interviews. Thus, 44 subjects participated in the study, $36 \mathrm{MtF}$ (82\%) and $8 \mathrm{FtM}$ (18\%) individuals ( - Table 1 ). The overall median age was 25.5 years (range: $18-59$ years). Most subjects were white,
Table 1 Anthropometric and demographic characteristics of the MtF and FtM subjects $(n=44)$

\begin{tabular}{|c|c|c|}
\hline Variable & & Number (\%) \\
\hline \multirow[t]{9}{*}{ Age (years) } & $18-21$ & $13(29.5)$ \\
\hline & MtF & $12(27)$ \\
\hline & FtM & $1(2.5)$ \\
\hline & $22-30$ & $21(48)$ \\
\hline & $\mathrm{MtF}$ & $19(42)$ \\
\hline & FtM & $3(6)$ \\
\hline & $\geq 31$ & $10(22.5)$ \\
\hline & MtF & $6(13.5)$ \\
\hline & FtM & $4(9)$ \\
\hline \multirow[t]{2}{*}{ Sex } & MtF (born as male) & $36(82)$ \\
\hline & FtM (born as female) & $8(18)$ \\
\hline \multirow[t]{2}{*}{ Color } & White & $30(68)$ \\
\hline & Black/Multiracial & $14(32)$ \\
\hline \multirow{3}{*}{$\begin{array}{l}\text { Relationship } \\
\text { status }\end{array}$} & Dating & $13(39.5)$ \\
\hline & Married/Stable union & $12(27.5)$ \\
\hline & No partner & $19(43)$ \\
\hline \multirow[t]{3}{*}{ Schooling } & Primary education & $8(18)$ \\
\hline & Secondary education & $30(68)$ \\
\hline & Higher education & $6(14)$ \\
\hline \multirow{2}{*}{$\begin{array}{l}\text { Occupational } \\
\text { status }\end{array}$} & Employed & $36(82)$ \\
\hline & Unemployed & $8(18)$ \\
\hline \multirow[t]{5}{*}{ Profession } & Unemployed & $8(18)$ \\
\hline & Hairdresser & $8(18)$ \\
\hline & Civil servant & $5(11.5)$ \\
\hline & Sex professional & $8(18)$ \\
\hline & Other & $15(34.5)$ \\
\hline \multirow{3}{*}{$\begin{array}{l}\text { Monthly } \\
\text { income* }\end{array}$} & None & $8(18)$ \\
\hline & 1 to 3 minimum wages & $25(57)$ \\
\hline & 4 to 6 minimum wages & $11(25)$ \\
\hline \multirow{4}{*}{$\begin{array}{l}\text { Residential } \\
\text { status }\end{array}$} & Partner & $12(27.5)$ \\
\hline & Parents & $19(43)$ \\
\hline & Alone & $4(9)$ \\
\hline & Other & $9(20.5)$ \\
\hline \multirow[t]{3}{*}{ Housing } & Rented & $14(32)$ \\
\hline & Ceded & $4(9)$ \\
\hline & Owned & $26(59)$ \\
\hline \multirow[t]{3}{*}{ Religion } & Catholic & $14(32)$ \\
\hline & Other & $13(32)$ \\
\hline & None & $16(36)$ \\
\hline
\end{tabular}

Abbreviations: FtM, female to male; MtF, male to female. Note: *Brazilian minimum wage: $\sim$ US $\$ 269.93$ per month. 
had graduated from high school, and were employed (-Table 1).

We also analyzed the clinical characteristics of the 44 subjects (-Table 2 ). The results indicate that most subjects wanted to undergo surgery for sex reassignment, many MtF subjects had previously self-medicated with a combined contraceptive based on ethinyl estradiol, and most subjects felt equally ( $p=0.99$ ) discriminated against in their social and family environments. There was a high rate of attempted suicide in this sample (MtF - 75\% versus FtM - 68.5\%; $p=0.66$ ). There was a higher rate of married FtM subjects in relation to married

Table 2 Clinical characteristics of the MtF and FtM subjects $(n=44)$

\begin{tabular}{|c|c|c|}
\hline Variable & & $\begin{array}{l}\text { Number } \\
(\%)\end{array}$ \\
\hline \multirow[t]{2}{*}{ Desiring surgery } & Neovaginoplasty & $34(94.5)$ \\
\hline & Mastectomy & $7(87.5)$ \\
\hline \multirow{2}{*}{$\begin{array}{l}\text { Hormone therapy } \\
\text { before treatment } \\
\text { at the University } \\
\text { Hospital }\end{array}$} & Yes & $39(88.5)$ \\
\hline & No & $5(11.5)$ \\
\hline \multicolumn{3}{|l|}{$\begin{array}{l}\text { Type of previous } \\
\text { hormone therapy }\end{array}$} \\
\hline $\mathrm{MtF}$ & $\begin{array}{l}\text { Combined contraceptive } \\
\text { Estradiol valerate }\end{array}$ & $\begin{array}{l}33(75) 1 \\
(2)\end{array}$ \\
\hline FtM & None Testosterone & $5(11.5)$ \\
\hline \multirow[t]{2}{*}{ STI } & Syphilis/HPV/Hepatitis B & $7(16)$ \\
\hline & HIV & $1(2)$ \\
\hline $\begin{array}{l}\text { Use of other } \\
\text { medications }\end{array}$ & Yes & $7(16)$ \\
\hline \multirow[t]{2}{*}{ MtF } & Antidepressant & 4 \\
\hline & Antiretroviral & 1 \\
\hline \multirow[t]{3}{*}{ Habits } & Smoking & $11(25)$ \\
\hline & Use of alcohol & $9(20.5)$ \\
\hline & Use of illicit drugs & $4(9)$ \\
\hline \multirow{3}{*}{$\begin{array}{l}\text { Age at sexarche } \\
\text { (years) }\end{array}$} & Had no sexarche & $1(2)$ \\
\hline & $<19$ & $39(88)$ \\
\hline & $>20$ & $4(10)$ \\
\hline \multirow{2}{*}{$\begin{array}{l}\text { Number of } \\
\text { partners }\end{array}$} & $<20$ & $21(47.5)$ \\
\hline & $>20$ & $23(52.5)$ \\
\hline \multirow{5}{*}{$\begin{array}{l}\text { Does he/she feel } \\
\text { discriminated? }\end{array}$} & Yes & $39(88.5)$ \\
\hline & Socially & $39(100)$ \\
\hline & On the job & $24(61.5)$ \\
\hline & By family & $14(36)$ \\
\hline & At the hospital & $7(18)$ \\
\hline \multirow{3}{*}{$\begin{array}{l}\text { Suicide attempt } \\
\text { and perceived } \\
\text { cause }\end{array}$} & Yes & $32(72.5)$ \\
\hline & FtM & $5(15)$ \\
\hline & $\mathrm{MtF}$ & $27(85)$ \\
\hline
\end{tabular}

Table 2 (Continued)

\begin{tabular}{|c|c|c|}
\hline Variable & & $\begin{array}{l}\text { Number } \\
\text { (\%) }\end{array}$ \\
\hline & -Social prejudice & $20(62.5)$ \\
\hline & $\begin{array}{l}\text {-Lack of acceptance } \\
\text { by the family }\end{array}$ & $15(47)$ \\
\hline & $\begin{array}{l}\text {-Discrimination } \\
\text { on the job }\end{array}$ & $6(19)$ \\
\hline & $\begin{array}{l}\text {-Lack of acceptance } \\
\text { of one's body }\end{array}$ & $21(67)$ \\
\hline \multirow{7}{*}{$\begin{array}{l}\text { Age at attempted } \\
\text { suicide (years) }\end{array}$} & $<19$ & $18(41)$ \\
\hline & FtM & $1(6)$ \\
\hline & $\mathrm{MtF}$ & $17(94)$ \\
\hline & $>20$ & $14(32)$ \\
\hline & FtM & $4(28.5)$ \\
\hline & $\mathrm{MtF}$ & $10(71.5)$ \\
\hline & None & $12(27)$ \\
\hline \multirow{2}{*}{$\begin{array}{l}\text { Mental health } \\
\text { treatment }\end{array}$} & Psychiatric & $6(13.5)$ \\
\hline & Psychological & $10(22.5)$ \\
\hline
\end{tabular}

Abbreviations: FtM, Female to Male; HPV, human papillomavirus; MtF, Male to Female; STI, sexually transmitted infection (reported and registered in the medical records).

MtF subjects (89.47\% versus $10.53 \%$ respectively; $p<0.01$ ). Male to female subjects were more likely to live with their parents or alone than FtM subjects (89.47\% versus $10.53 \%$ and $80 \%$ versus $20 \%$ respectively; $p=0.04$ ).

The analysis of the HADS results indicated that the rates of depression (82\%), and anxiety (100\%) were very high in the studied population (-Table 3 ). There were no significant associations between anxiety and attempted suicide $(p=0.27)$, cohabitation status $(p=0.59)$, feelings of discrimination ( $p=0.99)$, age $(p=0.23)$, and economic status $(p=0.25)$ in the MtF sample. There were no significant associations between depression and attempted suicide

Table 3 Prevalence of anxiety and depression among the MtF and FtM subjects $(n=44)$

\begin{tabular}{|l|l|l|}
\hline Instrument & \multicolumn{2}{l|}{ Number (\%) } \\
\hline & No & Yes \\
\hline Anxiety (HADS-A $\geq 8)$ & & \\
\hline MtF & 0 & $36(100)$ \\
\hline FtM & $1(12.5)$ & $7(87.5)$ \\
\hline Depression (HADS-D $\geq 9)$ & & \\
\hline MtF & $7(19.4)$ & $29(80.6)$ \\
\hline FtM & $1(12.5)$ & $7(87.5)$ \\
\hline
\end{tabular}

Abbreviations: FtM, female to male; HADS, Hospital Anxiety and Depression Scale; HADS-A, anxiety score of the HADS (range: 0-21); HADS-D, depression score of the HADS (range: 0-21); MtF, male to female. 
( $p=0.15)$, cohabitation status $(p=0.06)$, feelings of discrimination ( $p=0.53)$, age ( $p=0.72)$, and economic status $(p=0.50)$ in this sample. There was a tendency of depression to be more likely to develop among those living alone (100\%), with their parents $(94.2 \%)$, or with other people (79\%) than among those married or living with partners (50\%; $p=0.06)$. Depression was marginally more likely to occur in individuals who were single $(94.12 \%)$ or dating (84.64\%) than in those who were married (50\%), according to Fisher's exact test $(p=0.05)$. These analyses were not performed for the FtM group due to the small sample size.

The logistic regression analysis indicated that regarding the MtF subjects older than 30 years, attempted suicide was 1.49-fold more likely in adolescents (18-21 years-old), although these differences were not statistically significant $(p=0.89)$. There were also no significant associations between attempted suicide and cohabitation status and age ( $p=0.99$ for all). The small sample size of the FtM group did not permitenable the logistic regression analysis.

\section{Discussion}

There has been increasing interest in GD in recent decades, especially in developing countries, in particular in Brazil. Care for this population is regulated by ethical and legal standards that seek to preserve the right of a person to adopt his/her gender of choice and to achieve congruence between body and mind, regardless of the sex at birth. Contemporary Western societies have gone through significant transformations, and the multiple sexual relationships outside the binary malefemale standard are currently being discussed. ${ }^{21}$

The preponderance of $\mathrm{MtF}$ (82\%) over $\mathrm{FtM}(18 \%)$ subjects is an interesting finding of the present study, and is in agreement with the findings of a similar study conducted in The Netherlands during the 1990 s. $^{22}$ This predominance of MtF individuals may simply be because they are more likely to seek care than FtM individuals; the true numbers of MtF and FtM individuals are difficult to determine because of the limited access to the public health systems in developing countries, where such care is limited, and few services are available. Only four public health services in Brazil (in the States of São Paulo, Rio de Janeiro, Porto Alegre, and Goiás) provide full care to transsexuals, and individuals may have to wait many years for sex reassignment surgery. European studies have indicated a significant increase in the number of MtF individuals seeking treatment since the 1980s, possibly due to the increasing availability of the treatment. ${ }^{23,24}$ A study in Croatia indicated a 3:2 ratio of MtF over FtM individuals, ${ }^{23}$ and a study in Serbia indicated a ratio close to 1:1 (71 MtF versus 76 FtM individuals). ${ }^{24}$

In the present population, $29.5 \%$ of the subjects were 18 to 21 years-old, $48 \%$ were 22 to 30 years-old, and $22.5 \%$ were 31 years-old or older. Almost $1 / 3$ of these transsexuals lived with partners, most had graduated from high school, and only $6 \%$ had progressed to higher education. These results are comparable to those reported for transsexuals in Serbia, in which $79 \%$ of the MtF and $69 \%$ of the FtM subjects had graduated from high school, and $80 \%$ of the MtF and 3.6\% of the FtM subjects had progressed to higher education. ${ }^{24}$
Interestingly, most of our subjects were employed, and less than $20 \%$ of them worked as sex professionals. This is a positive result, and it may indicate that society is becoming less prejudiced against transsexuals, who used to be automatically labeled as sex workers. ${ }^{25}$ Most of our subjects had monthly incomes of one minimum wage or higher, indicating that they could be considered as members of the middle class. The Brazilian Secretary Office for Strategic Issues of the Presidency of the Republic defines the middle class as consisting of individuals who live in families with a per capita monthly income between US $\$ 291$ and US $\$ 1,019$; there is also a low-middle class (monthly income between US $\$ 102.36$ and US\$155.12), a mid-middle class (monthly income between US\$155.12 and US\$225.47), and an uppermiddle class (monthly income between US\$225.47 and US \$358.42). ${ }^{26}$ However, our results regarding income should be viewed with caution, because these data were self-reported.

A result to be underscored is that $88.5 \%$ of the sample of the present study reported they felt discriminated against by society, their families, at their work places, and in healthcare institutions (in decreasing order of importance). In parallel, more than $80 \%$ suffered from anxiety and/or depression, and $72 \%$ reported suicide attempts. In general, the rate of attempted suicide is more than 20 -fold higher among adult transsexuals than among the general population. ${ }^{27}$ A recent study summarized the results of multivariate models that evaluated factors associated with suicide attempts. During life, in the multivariate analysis model including sociodemographic factors, transgender MtF identity and being white were significantly associated with a decreased likelihood of suicide attempts. Participants who reported schooling until higher education had lower odds of attempting suicide throughout life compared with participants who had lower levels of schooling. In addition, higher levels of internalized transphobia were significantly associated with increased odds of attempting suicide throughout life. ${ }^{28}$

The results obtained in the present study also suggest the importance of a family support network to help individuals cope with difficulties during the period of discovery and treatment of GD. A previous study also reported that $41 \%$ of trans people who did not receive family support attempted suicide. ${ }^{29}$ Another study reported that transsexuals rejected by their families had an 8-fold higher risk of attempting suicide than those who had family support. ${ }^{18}$ A 2009 study in the United States reported that transsexuals have a 4 -fold higher risk of attempting suicide than heterosexuals. ${ }^{30}$ Our literature review indicated that few studies have examined the prevention of suicide in transsexuals. The identification of protective factors is vital for the development of methods to prevent suicide. Social support by friends and family is known to protect non-transsexuals at risk of suicide, so these should also protect transsexual individuals. A previous study with 113 transsexuals reported that social support from friends and family was associated with a $33 \%$ reduced risk of attempting suicide. ${ }^{29}$ Transsexuals are victims of discrimination and violence, even in developed countries, and this may lead to severe depression, thoughts of suicide, ${ }^{9}$ and attempted suicide. A study conducted in different European countries from January 2007 to October 2010 reported that 38\% 
of the individuals with gender identity disorder had symptoms of anxiety and depression, a rate much higher than that of the general population. ${ }^{31}$ An important finding of the present study is that living with a partner or being married provided protection against depression. This confirms the importance of an affective relationship for the emotional support of transsexuals, as previously discussed. ${ }^{32,33}$

Two-thirds of our sample declared having a religion. This is important, because having religious beliefs protects against risky behaviors (drug and alcohol use, smoking, unprotected sex, and multiple sex partners) in certain populations, adolescents in particular. ${ }^{34}$ Interestingly, only about a quarter of the present population reported use of alcohol and tobacco, about half the rate previously reported for transsexual individuals. ${ }^{12,35}$ Another study reported a greater use of marihuana, alcohol, and cocaine among transsexuals. ${ }^{36}$ There is some evidence that individuals with non-traditional sexuality tend to make more use of psychoactive substances that are harmful to health ${ }^{12}$ due to their higher levels of stress.

A previous research indicated that a higher percentage of transsexuals engaged in risky behavior by having sexual relations with more than 20 partners, and this may predispose this population to a higher risk of contracting an STI or HIV. ${ }^{11}$

In the present study, $77 \%$ of the MtF subjects wanted to undergo neovaginoplasty procedures, and $16 \%$ of the FtM subjects wanted to undergo mastectomies. In addition, 88.5\% of them reported using contraceptives based on ethinyl estradiol. However, this result may be overestimated, since our sample comes from an outpatient clinic devoted to treat trans people, and most of these patients ask for surgery to adequate their genitalia. There is evidence that many trans people do not wish to undergo surgery, and seek health services only to safely monitor their hormones. ${ }^{37,38}$ The risk of death is $51 \%$ higher among the transsexual population than among the general population, and the use of high-dose hormone therapy contributes to the higher risk of death among this population. ${ }^{39}$ In fact, a 1989 study reported an increased risk of heart disease and hyperprolactinemia with the use of ethinyl estradiol at a dose of $100 \mu \mathrm{g} / \mathrm{day}$, and that this led to a 41-fold higher risk of venous thromboembolism among transsexuals. ${ }^{40}$ Based on these findings, $17 \beta$-estradiol is now used instead of ethinyl estradiol. A more recent retrospective study that assessed the effect of hormone treatment on transsexuals who were treated for more than 10 years indicated no effect on cardiovascular risk or on the incidence of hormone-dependent cancer. ${ }^{41}$

Sex reassignment surgery by itself improves the emotional condition of transsexuals, ${ }^{42}$ and this procedure is fundamental in order for a transsexual person to feel fulfilled. The quality of the sex lives of transsexuals improves significantly after the full treatment, especially sex reassignment, because this improves self-esteem, the sexual response, and the expression of sexuality. After surgery, transsexual persons experience more orgasms and show greater commitment to the pursuit of sexual pleasure. ${ }^{15}$ A previous study with 118 transsexuals indicated increased psychological suffering (anxiety and depression) before the treatment when compared to 12 months after the treatment. ${ }^{43}$ In general, trans individuals who receive appropriate treatment report less psychological suffering, and even the prospect of impending surgery can reduce the high rates of anxiety and depression. ${ }^{44}$ There is also a marked reduction of psychopathology in transsexuals after the beginning of the hormone therapy and as the time for the surgery approaches. ${ }^{44}$ In the present study, being married or living with a partner were the two major factors associated with the decrease in the rates of depression and anxiety among transsexual individuals.

The quality of life of the trans population in developing countries is still precarious ${ }^{45}$ because of the small number of specialized services that care for these individuals. Appropriate medical and psychological treatment is widely recognized $^{46}$ as being important to improve the quality of life of this population. Thus, our results provide important new knowledge about the psychological distress faced by transsexual individuals due to discrimination by their families and by society in general; this distress may lead to high rates of anxiety and depression and alarmingly high rates of attempted suicide. These findings must be considered when developing the necessary treatments and care. Consideration of the psychological distress experienced by transsexual individuals, as documented in this article, may be useful for the development of improved patient interventions.

Learning more about the clinical, psychological, and social conditions of transsexual individuals can aid in the development of strategies for holistic support that may ameliorate their psychological distress and reduce the high rates of depression, anxiety disorders, and suicide. There is great interest in improving the care provided to transsexual individuals, and psychologists, physicians and other healthcare professionals, as well as legal professionals, have all devoted resources to this issue. However, scientific investigations on this issue are still quite scarce. The increased awareness of the transsexual condition and political activism by the transgender community certainly could help to improve this situation, but more efforts by healthcare providers are needed to address the specific psychosocial needs of transgender persons. We therefore suggest that multidisciplinary teams be used to improve the care provided to these vulnerable individuals.

\section{Conclusion}

The transsexuals evaluated in the present study were mostly middle-class MtF individuals who were employed and had graduated from high school. The study population had high rates of anxiety, depression, and attempted suicide. Living with a partner or being married appeared to protect against depression.

\section{References}

1 Drescher J. Queer diagnoses revisited: The past and future of homosexuality and gender diagnoses in DSM and ICD. Int Rev Psychiatry 2015;27(05):386-395

2 American Pasychiatric Association. Manual diagnóstico e estatístico de transtornos mentais: DSM-5. 5a ed. Porto Alegre: Artes Médicas; 2014 
3 Giami A, Beaubatie E. Gender identification and sex reassignment surgery in the trans population: a survey study in France. Arch Sex Behav 2014;43(08):1491-1501

4 Meyer WJ III. Comorbidity of gender identity disorders. Am J Psychiatry 2004;161(05):934-935, author reply 935

5 Selvaggi G, Bellringer J. Gender reassignment surgery: an overview. Nat Rev Urol 2011;8(05):274-282

6 Lobato MI, Koff WJ, Crestana T, et al. Using the Defensive Style Questionnaire to evaluate the impact of sex reassignment surgery on defensive mechanisms in transsexual patients. Rev Bras Psiquiatr 2009;31(04):303-306

7 Lobato MI, Schestatsky G, Schestatsky S, Henriques AA, Ghisolfi ES, Kegel S. Transexualismo: uma revisão. J Bras Psiquiatr 2001;50 (11/12):379-388

8 Cohen-Kettenis PT, Gooren LJ. Transsexualism: a review of etiology, diagnosis and treatment. J Psychosom Res 1999;46(04):315-333

9 Bazargan M, Galvan F. Perceived discrimination and depression among low-income Latina male-to-female transgender women. BMC Public Health 2012;12:663

10 Nemoto T, Bödeker B, Iwamoto M. Social support, exposure to violence and transphobia, and correlates of depression among male-to-female transgender women with a history of sex work. Am J Public Health 2011;101(10):1980-1988

11 Spizzichino L, Zaccarelli M, Rezza G, Ippolito G, Antinori A, Gattari P. HIV infection among foreign transsexual sex workers in Rome: prevalence, behavior patterns, and seroconversion rates. Sex Transm Dis 2001;28(07):405-411

12 Newcomb ME, Heinz AJ, Mustanski B. Examining risk and protective factors for alcohol use in lesbian, gay, bisexual, and transgender youth: a longitudinal multilevel analysis. J Stud Alcohol Drugs 2012;73(05):783-793

13 Giami A, Le Bail J. HIV infection and STI in the trans population: a critical review. Rev Epidemiol Sante Publique 2011;59(04):259-268

14 Sanchez NF, Sanchez JP, Danoff A. Health care utilization, barriers to care, and hormone usage among male-to-female transgender persons in New York City. Am J Public Health 2009;99(04):713-719

15 De Cuypere G, T'Sjoen G, Beerten R, et al. Sexual and physical health after sex reassignment surgery. Arch Sex Behav 2005;34(06):679-690

16 Derogatis LR, Meyer JK, Vazquez N. A psychological profile of the transsexual. I. The male. J Nerv Ment Dis 1978;166(04):234-254

17 Guzmán-Parra J, Sánchez-Álvarez N, de Diego-Otero Y, et al. Sociodemographic characteristics and psychological adjustment among transsexuals in Spain. Arch Sex Behav 2016;45(03):587-596

18 Grossman AH, D'Augelli AR. Transgender youth and life-threatening behaviors. Suicide Life Threat Behav 2007;37(05):527-537

19 Zigmond AS, Snaith RP. The hospital anxiety and depression scale. Acta Psychiatr Scand 1983;67(06):361-370

20 Cox DR. The analysis of binary data. London: Methuen; 1970

21 Merryfeather L. A personal epistemology: towards gender diversity. Nurs Philos 2011;12(02):139-149

22 van Kesteren PJ, Gooren LJ, Megens JA. An epidemiological and demographic study of transsexuals in The Netherlands. Arch Sex Behav 1996;25(06):589-600

23 Duisin D, Nikolić-Balkoski G, Batinić B. Sociodemographic profile of transsexual patients. Psychiatr Danub 2009;21(02):220-223

24 Vujovic S, Popovic S, Sbutega-Milosevic G, Djordjevic M, Gooren L. Transsexualism in Serbia: a twenty-year follow-up study. J Sex Med 2009;6(04):1018-1023

25 Ross B. Outdoor brothel culture: the un/making of a transsexual stroll in Vancouver's West End, 1975-1984. J Hist Sociol 2012; 25(01):126-150

26 Brasil. Governo Federal [Internet]. Governo diz que nova classe média tem renda entre R\$291 e R \$1.019 familiar per capita. 2012 [cited 2015 Feb 19]. Available from: <http://www.brasil.gov.br/ economia-e-emprego/2012/05/governo-diz-que-nova-classemedia-tem-renda-entre-r-291-e-r-1.019-familiar-per-capita>
27 Blosnich JR, Brown GR, Shipherd Phd JC, Kauth M, Piegari RI, Bossarte RM. Prevalence of gender identity disorder and suicide risk among transgender veterans utilizing veterans health administration care. Am J Public Health 2013;103(10):e27-e32

28 Perez-Brumer A, Hatzenbuehler ML, Oldenburg CE, Bockting W. Individual- and structural-level risk factors for suicide attempts among transgender adults. Behav Med 2015;41(03):164-171

29 Moody C, Smith NG. Suicide protective factors among trans adults. Arch Sex Behav 2013;42(05):739-752

30 Ryan C, Huebner D, Diaz RM, Sanchez J. Family rejection as a predictor of negative health outcomes in white and Latino lesbian, gay, and bisexual young adults. Pediatrics 2009;123(01):346-352

31 Heylens G, Elaut E, Kreukels BP, et al. Psychiatric characteristics in transsexual individuals: multicentre study in four European countries. Br J Psychiatry 2014;204(02):151-156

32 Steiner BW, Bernstein SM. Female-to-male transsexuals and their partners. Can J Psychiatry 1981;26(03):178-182

33 Kraemer B, Hobi S, Rufer M, Hepp U, Büchi S, Schnyder U. [Partner relationship and sexuality of female-to-male transsexuals]. Psychother Psychosom Med Psychol 2010;60(01):25-30

34 Kabiru CW, Elung'ata P, Mojola SA, Beguy D. Adverse life events and delinquent behavior among Kenyan adolescents: a crosssectional study on the protective role of parental monitoring, religiosity, and self-esteem. Child Adolesc Psychiatry Ment Health 2014;8:24

35 Ramirez-Valles J, Garcia D, Campbell RT, Diaz RM, Heckathorn DD. HIV infection, sexual risk behavior, and substance use among Latino gay and bisexual men and transgender persons. Am J Public Health 2008;98(06):1036-1042

36 Díaz RM, Heckert AL, Sánchez J. Reasons for stimulant use among Latino gay men in San Francisco: a comparison between methamphetamine and cocaine users. J Urban Health 2005;82(01, Suppl 1):i71-i78

37 MacDonald T, Noel-Weiss J, West D, et al. Transmasculine individuals' experiences with lactation, chestfeeding, and gender identity: a qualitative study. BMC Pregnancy Childbirth 2016; $16: 106$

38 Kuper LE, Nussbaum R, Mustanski B. Exploring the diversity of gender and sexual orientation identities in an online sample of transgender individuals. J Sex Res 2012;49(2-3):244-254

39 Asscheman H, Giltay EJ, Megens JA, de Ronde WP, van Trotsenburg MA, Gooren LJ. A long-term follow-up study of mortality in transsexuals receiving treatment with cross-sex hormones. Eur J Endocrinol 2011;164(04):635-642

40 Asscheman H, Gooren LJ, Eklund PL. Mortality and morbidity in transsexual patients with cross-gender hormone treatment. Metabolism 1989;38(09):869-873

41 Wierckx K, Mueller S, Weyers S, et al. Long-term evaluation of cross-sex hormone treatment in transsexual persons. J Sex Med 2012;9(10):2641-2651

42 Leinung MC, Urizar MF, Patel N, Sood SC. Endocrine treatment of transsexual persons: extensive personal experience. Endocr Pract 2013;19(04):644-650

43 Colizzi M, Costa R, Todarello O. Transsexual patients' psychiatric comorbidity and positive effect of cross-sex hormonal treatment on mental health: results from a longitudinal study. Psychoneuroendocrinology 2014;39:65-73

44 Heylens G, Verroken C, De Cock S, T'Sjoen G, De Cuypere G. Effects of different steps in gender reassignment therapy on psychopathology: a prospective study of persons with a gender identity disorder. J Sex Med 2014;11(01):119-126

45 Prado Cortez FC, Boer DP, Baltieri DA. A psychosocial study of male-to-female transgendered and male hustler sex workers in São Paulo, Brazil. Arch Sex Behav 2011;40(06):1223-1231

46 Costa EM, Mendonca BB. Clinical management of transsexual subjects. Arq Bras Endocrinol Metabol 2014;58(02):188-196 